\title{
The importance of rewards in the management of multisponsor loyalty programmes
}

Received (in revised form): 29th October, 2007

\section{Pedro Reinares Lara}

holds a PhD in Marketing (UCM, Spain). He has occupied responsible positions in leading companies as well as in several Spanish Universities. He is the author of six well-known books in the fields of marketing and communication. Nowadays, he combines his work as resident teacher in the Department of Marketing at Universidad Rey Juan Carlos de Madrid with his work as a consultant.

\section{Jesús García de Madariaga}

is Assistant Professor, Marketing Department, Universidad Complutense de Madrid (Spain). He has a PhD in Marketing and Business Administration in Advertising by Universidad Complutense de Madrid. His work focuses on several issues related to Customer Relationship Management and Marketing Information Systems. His research has been published in refereed international journals. He is also an active marketing research consultant.

\section{Keywords loyalty programmes, reward programmes, management of loyalty programmes}

\begin{abstract}
This work attempts to specify procedures to improve the management of loyalty programmes based on one of their structure elements: prizes or rewards. The starting point is the premise that the current classifications of prizes found in the academic literature focus on the offer, are reductionist, and only permit the establishment of eventual effects between such rewards and one part of the programmes (the monosponsor type). Therefore, from the programme users' viewpoint, we propose to contrast the importance of the rewards in comparison to other management elements. Subsequently, from a classification of incentives based on consumers' preferences, we will determine their interest in such rewards and establish the influence of these rewards on consumers' satisfaction with the programmes. The results will allow us to establish effective conclusions for the management of multisponsor programmes and will represent a basis of useful specific knowledge for future investigations focused on understanding this important marketing instrument.

Journal of Database Marketing \& Customer Strategy Management (2007) 15, 37-48. doi:10.1057/palgrave.dbm.3250066; published online 3 December 2007
\end{abstract}

Pedro Reinares Lara Department of Business Administration Area of Marketing Paseo de los Artilleros s/n 28032 Madrid Spain

Tel: +3491488 76 40; Fax: +34 913718950 ; e-mail: pedro.reinares@ urjc.es

\section{INTRODUCTION}

Loyalty programmes have become consolidated as a marketing instrument whose adoption in many sectors has not been associated with appropriate comprehension, either of their operative and management elements or of their effects. The limited development of knowledge of loyalty programmes is observed in the lack of consensus about their effects and benefits. Several authors ${ }^{1-5}$ have misgivings about their capacity to develop consumer loyalty. Other studies, however, acknowledge the contribution of these programmes to improve customer data systems, tracking of customers' transactions, and commercial investigation applied to managing the diversity of customers. ${ }^{6-12}$

The introduction of new programmes indicates that this is not a passing management fad. Therefore, the contribution of knowledge about them is beginning to 
be considered a priority, both from academic and business sections.

Loyalty programmes, appropriately managed, are considered to allow structured and effective actions to manage, select, relate, and control customers' buying behaviour. Many authors confer in pointing to the innovative management of a programme's incentives and rewards as an important element of its viability. Several authors ${ }^{4,10,13-16}$ acknowledge the relation between incentives or rewards and the possible positive effects on programme functioning, while others ${ }^{17-20}$ underscore the lack of previous theories about concrete elements of incentive management in these programmes. The lack of studies is also noted in the business setting (rewards are analysed as a function of their financial implications), so that the development of academic research is surely limited by the lack of data obtained in real settings.

Within this context, this work describes diverse programme incentives with the aim of subsequently proposing some practical advances to understand how they affect the functioning of these programmes. As will be presented in the following paragraphs, this research proposes three essential contributions:

- The analysis of multisponsor programmes. To date, academic research has not paid them the attention warranted by their quantitative development and their social importance.

- The empirical work focuses on the consumers and their preferences and perceptions of loyalty programmes.

Directly addressing consumer preferences of programme rewards is a novel approach to the study of these programmes.

- Lastly, we attempt to contribute some contrasted operative management bases that can be used by managers of multisponsor programmes. Business practice shows the need to contribute knowledge of reward management in the programmes.

Focusing research on multisponsor programmes is justified because of the scientific opportunity, and especially because of the growing development of this programme typology (30 per cent of the loyalty programme cards in Spain belong to multisponsor typologies, and this is a generalised tendency all over the world). At the same time, a large number of monosponsor programmes are incorporating companies associated with other sectors, evolving towards the characteristics of multisponsor programmes. ${ }^{21}$

The review of the literature shows that the most rigorous works focus mostly on programmes that allow one to value the effects of a direct association between the promoting company and the various elements of the programme structure: those of the monosponsor type. Business practise, however, cannot transfer its contributions to programmes in which the relation between the effects of the programme and the enterprise that promotes it is indirect. This is because, in multisponsor programmes, a large number of companies make up a management structure, and these companies have diverse goals whose only link with the consumer is the programme itself.

From this derives the need to contribute knowledge about the effects of the prizes and rewards in a programme structure that groups various companies, sectors, and products. Therefore, it is necessary to study how the rewards may contribute value and differentiation directly to the programme, independently of the goals of the participating companies. Whereas monosponsor programmes can offer the appropriate rewards to their segment of consumers and they may add value to the company image, multisponsor programmes must offer a broad range of rewards, given the heterogeneity of the participating 
companies and their consumers. With this condition, understanding the adequacy of these rewards, their perceived value, and their effects on the programme itself are crucial to improve their management and make them more dynamic.

\section{CONCEPTUAL FRAMEWORK}

\section{Relations among loyalty programmes and rewards}

The research works focusing on rewards attempt to understand how they are a key factor for the consumers' involvement and motivation in the programme. These works try to verify how their differentiated management affects the perceived value of the programme and the motivation to buy. $^{22}$ From an operative viewpoint, the influence of incentive management in programme viability has been studied by analysing the most pragmatic elements:

- The appraisal of the benefits between the management of an individualised programme or a multisponsor programme. $^{13}$

- Comparison of the apparently more successful incentives applied by the programmes and those that have obtained the worst results. ${ }^{10}$

- How to reduce the costs of such incentives. $^{23}$

These works agree about the suitability of contributing incentives directly related to the business that promotes the programme and preferentially aimed at consumers who display prior involvement toward the product-business source of the programme. Studying in depth the effects of the various typologies of incentives, Roehm et al. ${ }^{14}$ present the following criteria:

- If the programme's goal is to influence short-term buying behaviour, tangible incentives are more appropriate than intangible ones.
- If the goal is to reinforce the relation between the company and the customer, at the beginning of a loyalty programme, intangible incentives are more effective.

As concrete incentives, they mention privileges or individualised services based on acknowledgement of the consumer's personal characteristics.

- The time dimension of the reward is also important. Immediate rewards are preferable to change short-term behaviour. This is nothing new, because from the operative viewpoint, it refers to analysing the effects of a conventional sales promotion.

- Establishing a long-term relation, seeking stable modification of consumer behaviour requires deferred incentives.

These contributions are clearly at odds with the operative developed by multisponsor programmes (accumulation of points over a long period of time depending on the buying volume, which are exchanged for rewards without any relation to the brand that develops the programme). Given that many programmes are applied in scarcely differentiated and low-involvement product markets, it is essential to analyse whether the limited results of the programmes can be explained according to the former proposals. Although we do not intend to undervalue these sources, for the majority of the programmes, the delivery of rewards is obtained by means of the accumulation of points for exchange.

The lack of consensus about an empirically validated proposal that would allow companies to optimise their offer of programme rewards can be observed when consulting the diverse sources. Thus, several authors $^{24,25}$ indicate how complex it is to determine the most suitable incentive typology according to the former sources. The proposal of programme incentives has to do with consumer-related variables, such as the purchase volume, the consumer's sociodemographic profile, or their level of 
loyalty to the company after participating in the programme operation. In short, it is doubtful whether one can generalise about the ideal reward typologies.

Regarding the other sources consulted, it can be concluded that the contributions about the adequate reward typology as a function of consumer involvement in the company, ${ }^{14,19,26}$ their motivations, ${ }^{17,22}$ their previous satisfaction, ${ }^{27}$ maximisation of economic benefits, ${ }^{28}$ the emotional associations promoted by programmes, ${ }^{29,30}$ or the coherence between the type of reward and the company image ${ }^{16}$ cannot be transferred to a multisponsor programme structure.

Therefore, it would not be methodologically viable to analyse certain programme effects such as loyalty, modification of buying behaviour, or the associations between the programme and the company without first having taken into consideration how current rewards and their relations within a multisponsor programme structure are valued.

\section{Attributes of a loyalty programme structure}

In order to determine whether or not incentives are important to consumers' perception of the programmes, which this work attempts to corroborate, we started out with the contributions of Wulf et al. ${ }^{31}$ They established the existence of five internal attributes (costs) and three external ones (benefits), subsequently contrasting their influence in consumers' decision to participate in a specific programme.

- Personal data to participate in the programme: As consumers are disinclined to facilitate certain data to the companies, this can be a factor that moderates their desire to participate in the programme.

- Participation cost: A certain amount of money that has to be paid in order to be able to participate in loyalty programmes.

- Buying volume and frequency: Consumers who buy more are more favourable to the programmes because they have more access to the rewards.

- Exclusiveness of the programme: Whether the programme is massive or, on the contrary, it is restricted to a specific group of consumers.

- Participation effort: This values the complexity of the procedures of using and collecting information about the programme.

As external factors (benefits), the authors define three:

- Programme rewards: What consumers obtain by participating in the programme.

- Number of companies that participate in the programme.

- Temporality of the programme: The time interval during which the programme benefits are available.

In view of the methodological limitations of their contributions, we recommend a subsequent contrast of the attributes proposed as optimum to account for consumers' appraisal of the diverse programme options.

\section{GOALS AND HYPOTHESES}

This investigation attempts to validate the contributions of sources with methodological limitations such as small sample size or the lack of information about the profile of consumers who do not participate in the programmes.

The contributions of the sources consulted cannot be transferred to the operative management of multisponsor programmes, because the latter include various companies and consumers who are related to them through very different motivations. Despite the interest of the referenced sources, they are insufficient to be integrated into empirical developments aimed at the comprehension of the effects of rewards within a multisponsor programme structure. The relevance of the goals proposed in this work is essential for the management and 
dynamisation of loyalty programmes. In this sense, only one-fourth of the consumers consider that loyalty programme incentives actually meet their needs. ${ }^{15}$ Likewise, analysis of business practise reinforces the relevance of this work. An overview of the typologies of incentives used by the programmes reveals the limited imagination of programme managers. The rewards are not only very similar among programmes from the same sector (eg, in food brands), but this similarity also occurs in programmes in general.

The success of a loyalty programme will depend to a great extent on improving the perceived value of the rewards offered. ${ }^{22}$ This reinforces the potential interest of applying an investigation about the most recommendable kind of incentives.

Starting from a classification of rewards elaborated by programme users, ${ }^{21}$ empirical application could be promoted that would determine the adequacy and the possible effects of the rewards conditioned by a multisponsor programme. Thus, in this work, we will specify the possible effect of the different kinds of rewards on global satisfaction with the loyalty programme. Hence, the initial goal of the work will be to determine whether rewards are the most important operative element of the programmes for the participants in multisponsor loyalty programmes, as various sources argue. Subsequently, this work will propose a series of basic goals that will allow improvement of the design of these programmes. For this purpose, we formulated the following working hypotheses about the demand for incentives:

$\mathbf{H}_{1}$ : For the participants in these programmes, rewards are the most important management element of multisponsor loyalty programmes.

$\mathbf{H}_{2}$ : The degree of satisfaction of current and potential users of multisponsor cards is related to the kind of incentives received.
$\mathbf{H}_{3}$ : There are obvious differences between users and nonusers of multisponsor loyalty cards as a function of their appraisal of the incentives offered (or to be offered).

\section{RESEARCH DESIGN}

As mentioned, this work initially attempts to specify how current users and nonusers value the rewards offered at present by loyalty programmes as well as other rewards that they consider adequate. With this aim, we incorporated into the questionnaire a classification of incentives proposed in prior works, ${ }^{21}$ whose added value is that it is elaborated from the point of view of the demand (the programme users). The purpose of this reward classification was to incorporate typologies not proposed massively till now by Spanish loyalty programmes, which would be useful in subsequent investigations. The description of the prizes is displayed in Table 1 .

These 13 incentives were incorporated into the questionnaire by means of a series of questions to determine the degree of interest (perceived value) of the reward typologies for current and potential users of current multisponsor loyalty programmes. Each one of the 13 incentives was rated on a 10-point Likert scale, ranging from 1 (I don't like it at all) to 10 (I like it very much). ${ }^{32}$ Satisfaction with the programme was measured with a similar scale, both for the sample of users (card-holders) and that of nonusers $(1=$ extremely unsatisfactory; $10=$ extremely satisfactory). These scales were used in the investigation of loyalty programmes. ${ }^{27}$ More complex scales to measure satisfaction with the programme were discarded in order to match the number of questions to the methodological limitations of data collection. This questionnaire also incorporated as essential preliminary questions for the purpose of the investigation in the evaluation of the seven attributes that Wulf et al. ${ }^{31}$ considered 
Table 1: Denomination and content of the possible rewards of a loyalty programme

Personal tangibles
Utilitarian tangibles
Amusement tangibles
Amusement intangibles
Tourism
Discounts
Information
Leisure
Culture
Services
Social benefits
Solidarity
Ecology

Table 2: Technical research card
Fashion, complements, glasses, costume, jewelry, etc.

Daily practical needs such as a small electric appliance for the home. Musical equipment, DVDs.

Contests, raffles, games.

Trips, hotels, airline tickets.

Direct or indirect price reduction.

Reports about health, stock market, fashion, cars, etc. ...

Restaurants, bars, amusement parks.

Tickets to the cinema, exhibitions, museums, cooking courses, concerts.

Guarantees, maintenance, fast delivery.

Exclusiveness, preference, prestige.

Social ends for disadvantaged third parties.

Saving energy, protecting the environment.

\begin{tabular}{ll}
\hline Universe & Residents in Spain, over 18 years of age. \\
Sample unit & Active users of at least one multisponsor loyalty programme and their \\
& sociodemographic equivalent in nonusers \\
Geographic sample area & Spain (stratified as a function of sex, age, mosaic group, number of \\
& members of family unit, and amount of time in the programme). \\
Data collection method & Personal survey by phone, administering a structured questionnaire (CATI). \\
Sample size & Foreseen: 550 programme users and 550 nonusers of programmes. \\
& Final: 521 programme users and 540 nonusers of programmes. \\
Sample error & $\pm 3.07 \%$ \\
Confidence level & $95 \% Z=1.96$ \\
Sampling procedure & Stratified sample. \\
Maximum variance admitted & $p=q=50 \%$ \\
Field work card & Between October and November of 2005. \\
\hline
\end{tabular}

conditioned participation in a programme. The attribute 'participation costs' was not included because the prior descriptive information of the programmes indicated that, in all cases of multisponsor programmes, there are no registration fees.

The questionnaire, as shown in the technical card of the research in Table 2, was administered in the form of personal surveys by a computer-assisted telephonic interview. The order of the incentives and their appraisal were automatically rotated so as to avoid the negative bias associated with a long telephone questionnaire.

The distribution of the sample among the various levels that define the sociodemographic profile of loyalty programme users corresponds with the universe of the same according to sources from the two majority multisponsor programmes in Spain, which group about five million users. It is noteworthy that, when sampling, the proportion of the levels between card-holders and nonusers was exactly respected. The justification of these proportions was carefully valued. If, according to the investigation goals, we wished to compare the differential evaluation of the incentives among active loyalty programme participants and nonusers, it seems logical that this comparison should be carried out among sociodemographically equivalent profiles. A different sample representation of non-users would provide erroneous contributions from the start, as the population as a whole is not a potential user of loyalty programmes. This limitation is frequent in the works consulted. In these works, conclusions are reached about card-holders; however, their behaviour before obtaining the card is unknown, the same as whether the attributed effects are accounted for by obtaining the card or by intrinsic elements of that profile, such as, for example, prior affinity with the establishment. Neither is it appropriate to compare card-holders' behaviour with the profile of the population 
as a whole, because it has been shown that loyalty programme participants present a higher level of consumption than the rest of the population. ${ }^{4}$

\section{RESULTS}

In order to contrast the first hypothesis $\left(\mathrm{H}_{1}\right)$, we began with the favourable results about the importance of the programme rewards. Both for the users and the nonparticipants in loyalty programmes, programme prizes are the determining attribute to predispose people to participate in a concrete programme. In this sense, we can interpret that the main cause of nonusers' refusal to participate in loyalty programmes is not because they do not know about the programmes, but because they perceive the rewards to be inadequate in comparison to the effort required (see Table 3).

In order to determine whether the mean scores of the two populations (card-holders vs. nonusers; null hypothesis) were equal, we used the $t$-test for independent samples. This contrast determines whether the differences between card-holders and nonusers (dependent variable) were significant, based on their responses about the importance of the prizes. It was observed that the importance of the benefits for nonusers was higher than that for card-holders $(p<0.000)$.

The second hypothesis was first contrasted with correlational analysis that later allowed us to develop an explanatory model by regression analysis.

All the prizes correlated positively (significant at the level of $p<0.001$ ),

Table 3: Importance of the attributes of a L.P

\begin{tabular}{lll}
\hline & Card-holder & Nonuser \\
\hline Personal data & 5.9 & 6.3 \\
Purchase volume/ & 7.0 & 7.1 \\
frequency & & \\
Exclusiveness & 4.0 & 4.3 \\
Effort & 7.0 & 6.8 \\
Number of company & 8.0 & 8.2 \\
participants & & \\
Benefits-rewards & 8.9 & 9.2 \\
Time-limit of benefits & 6.2 & 6.2 \\
\hline
\end{tabular}

although many of the descriptive values were lower than 0.5 . In the nonuser group, the association of satisfaction with amusement intangibles prizes and services was notable, whereas in the group of cardholders, satisfaction was associated with discounts and amusement intangibles prizes. Among the prizes, the highest correlation noted was between ecology and solidarity $(r=0.765, p<0.01)$. These prizes, which are absent in most of the portfolios of prizes offered in the area of loyalty cards, also obtained the second and the third highest mean scores in general. This leads us to conclude the importance of including prizes from both these groups to increase levels of satisfaction. The weakest relation was the one found between tourism and utilitarian tangibles $-r=-0.04$ and 0.106 for card-holders and nonusers, respectively. This indicates that people who value tourism prizes do not value utilitarian tangibles and vice versa. In general, tourism had little relation with the other prizes (ie, it had a very weak relation with discounts, $r=0.15$, and with personal tangibles, $r=0.11)$.

Multivariate regression was used to transfer these observations to an equation of the relations under study. The condition that there should be a substantial number of correlations of over 0.5 for a regression analysis to be suitable was met, although somewhat restrictively. Using the step-wise method, we selected a model that predicted being a card-holder. With this model, we hoped to find differences in the profile of the attitude towards the card. More specifically, we hoped to find which incentives related to loyalty cards could explain satisfaction significantly. We performed an analysis, differentiating by groups, and the results were discouraging. In the case of potential card-holders, although the model showed that their satisfaction was a function of the presence of prizes such as services, amusement tangibles, solidarity, and amusement intangibles, the determination 
coefficient was only 0.24 (the goodness of fit of the model is rejected). The same problem occurred among card-holders, where the value only reached 0.317 , with the following prizes being significant: amusement intangibles, amusement tangibles, tourism, personal tangibles, and ecology.

To contrast the third hypothesis, various previous descriptive analyses were carried out to examine the importance of each kind of reward in the surveyed individuals on a score ranging from 1 to 10 .

Initially, we carried out a descriptive analysis of the rewards for each group. The results are presented in Table 4.

The highest mean scores are for tourism (7.6), solidarity (7.3), ecology (7.3), and amusement tangibles (7.2). Despite the fact that tourism obtained the highest mean score of these four prizes, solidarity and ecology were noteworthy because, in addition to their higher variability, their maximum values were more frequent, both

Table 4: Descriptive statistics

\begin{tabular}{lllll}
\hline Prizes & Type of user & & $\boldsymbol{M}$ & s.d. \\
\hline Personal & Loyalty card & No & 5.41 & 1.75 \\
tangibles & & Yes & 5.41 & 1.84 \\
Utilitarian & Loyalty card & No & 5.47 & 1.89 \\
tangibles & & Yes & 5.33 & 1.78 \\
Amusement & Loyalty card & No & 5.66 & 2.00 \\
(intangible) & & Yes & 5.32 & 1.97 \\
Amusement & Loyalty card & No & 7.28 & 1.60 \\
tangibles & & Yes & 7.07 & 1.64 \\
Tourism & Loyalty card & No & 7.59 & 1.83 \\
& & Yes & 7.54 & 1.72 \\
Discounts & Loyalty card & No & 6.52 & 1.87 \\
& & Yes & 6.66 & 1.70 \\
Information & Loyalty card & No & 5.46 & 1.90 \\
& & Yes & 5.54 & 1.79 \\
Leisure & Loyalty card & No & 6.30 & 1.79 \\
& & Yes & 6.33 & 1.69 \\
Culture & Loyalty card & No & 6.60 & 1.76 \\
& & Yes & 6.56 & 1.80 \\
Services & \multirow{2}{*}{ Loyalty card } & No & 6.84 & 1.99 \\
& & Yes & 6.66 & 1.83 \\
Social benefits & Loyalty card & No & 5.88 & 2.03 \\
& & Yes & 6.04 & 1.95 \\
Solidarity & Loyalty card & No & 7.50 & 1.97 \\
& & Yes & 7.14 & 1.98 \\
Ecology & Loyalty card & No & 7.42 & 2.04 \\
& & Yes & 7.19 & 2.07 \\
\hline & & & & \\
\hline
\end{tabular}

Perceived prize value for card-holders and for nonusers. In tourism, however, only the nonusers' most frequent score was maximum. In fact, of all the options presented, these were the ones with the greatest differences among cardholders $\left(\chi^{2}\right.$ (solidarity) $=10.673, p<0.05$ and $\chi^{2}($ ecology $\left.)=6.126, p<0.05\right)$.

The lowest mean scores were for personal tangibles (5.4), information (5.5), utilitarian tangibles (5.4), and amusement intangibles (5.3). The lowest score in card-holders was for amusement intangibles, with the most frequent value being 5.5 , and it also had the greatest dispersion. In nonusers, the lowest score was for personal tangibles (5.41), with the most frequent value being 5 . The case of amusement intangibles is noteworthy, as it had a very low mean score (5.66), a mode of 7.5, and the greatest dispersion among the worst-valued prizes. This may be due to the large number of medium-low scores, despite also obtaining high scores.

Regarding the sociodemographic variables (sex, mosaic typology, number of members at home, and age), no significant differences were found between holders and nonusers of multisponsor loyalty cards. It should be remembered that in the sampling distribution, we respected the proportion of the levels of the universe of card-holders and nonusers.

To determine whether the means of the two populations were equal (null hypothesis), we transformed the variables into fictitious variables. Specifically, to study whether there were significant differences in card-holders' scores compared to nonusers, we carried out a Student's $t$-test for independent samples. It was observed that amusement, amusement tangibles, and solidarity generated significant differences between non-users and card-holders. In the three cases, the nonusers scored higher in these incentives (Table 5).

Once these bi-variable analyses were performed, we proceeded to elaborate models based on various procedures as a function of the nature of the scales used. 
Various ways to establish the relations between a dependent variable and one or several independent variables have been proposed. In order to guarantee that the groups are, in effect, different and there is no overlapping, we carried out discriminant analysis and CHAID analysis.

To contrast which kind of prize is more attractive for the market sector, ${ }^{33}$ we attempted to differentiate the sample as a function of their appraisals of the various incentives, categorised into two groups: card-holders and nonusers. For each case, the independent variables were the scores given to the proposed incentives. ${ }^{34}$

As the sample was sufficiently large, it was divided randomly into two parts. Discriminant analysis was conducted on 466 individuals, using the remaining cases to verify the validity of the results. As there were two groups, a linear function was estimated, which was the linear combination of the variables solidarity, discounts, and amusement, with their corresponding nonstandardised coefficients.

The programme used for this analysis selected, by means of the step-wise method, the most discriminating variables using Wilks' lambda statistic and introducing the variable that minimised this statistic. As the variables did not differ in the measurement unit, these coefficients can be used as indicators of their relative importance, with the variables with higher coefficients

Table 5: Mean prize scores that yielded significant differences

\begin{tabular}{llll}
\hline Prizes & Nonuser & Card-holder & Significance \\
\hline Amusement & 5.66 & 5.32 & 0.008 \\
Amusement & 7.28 & 7.07 & 0.035 \\
tangibles & & & 0.030 \\
Solidarity & 7.50 & 7.14 & \\
\hline
\end{tabular}

contributing more. The sign of the coefficients shows the direction of their relation with the variable to be explained; if it is positive, there is a direct relation with the fact of being a card-holder, or an inverse relation if the sign is negative. The eigenvalue of 3.394 and the low canonical correlation of 0.13 indicates that the discriminant variables do not allow differentiation of the groups. The value of lambda was very low (0.06), which indicates that the groups overlap. Despite the transformed value of lambda $\left(\chi^{2}(3)=105.098, p=0.000\right)$, we cannot reject the null hypothesis that the groups compared have equal means in the discriminant variables (Tables 6 and 7).

The result of the discriminant analysis is reflected in the transition matrix that determines whether membership in the group as predicted by the function coincided with the survey's real group membership. Examination of the validation results shows that only in 57.4 per cent of the cases did the real value of belonging to a group coincide with the group predicted by the discriminant function. Taken by groups, this percentage is higher for the segment of nonusers (58.3 per cent) than for the group of card-holders (56.4 per cent).

In view of the scarce explanation reached by an aprioristic method (discriminant analysis), we selected an optimising method, specifically a decision tree. In this case, a variable is defined as dependent (whether or not an individual is a multisponsor

Table 7: Wilks' Lambda

\begin{tabular}{lllll}
\hline $\begin{array}{l}\text { Function } \\
\text { contrast }\end{array}$ & $\begin{array}{l}\text { Wilk's } \\
\text { lambda }\end{array}$ & Chi-square & d.f. & $\boldsymbol{p}$ \\
\hline 1 & 0.974 & 23.602 & 3 & 0.000 \\
\hline
\end{tabular}

Table 6: Canonical correlation

\begin{tabular}{lllll}
\hline Function & Eigenvalue & \% of variance & Accumulated $\%$ & Canonical correlation \\
\hline 1 & $0.026^{*}$ & 100.0 & 100.0 & 0.160 \\
\hline
\end{tabular}

*The first discriminant canonical functions were used in the analysis. 
card-holder) and the goal is to understand what leads to this variable and how this variable is segmented. Under these circumstances, CHAID or CART is preferred to develop a predictive model. ${ }^{35}$ In other words, this problem can be treated by means of a model based on adjusted decision trees with statistical capacity. ${ }^{35}$ CHAID is used when the following components are presented: a categorical dependent variable and a set of categorical independent variables. ${ }^{36}$ The result is a classification tree that shows how certain forms of predictor variables differentiate the predicted dependent variable.

There seems to be a moderate inverse association between being a card-holder and the score given to amusement incentives. As the score given to this incentive decreases, the level of being a card-holder increases. No significant differences were observed in these groups with regard to any other kind of reward. Likewise, and only among those who scored below seven in the amusement prizes, more interest was observed in social benefits. The probability of being a cardholder in this group increased by 27.55 per cent with regard to the distribution of the root node (Table 8).

\section{IMPLICATIONS FOR MANAGEMENT AND FUTURE LINES OF RESEARCH}

Among the different elements of the operative structure of a loyalty programme, rewards are considered to be the most important. They are even considered more important among nonusers than among card-holders.

The relation of the structure of the prizes offered to satisfaction with the programmes has been shown, although other variables related to other operative elements of the programmes should be incorporated to account for satisfaction variability.

Table 8: Decision tree

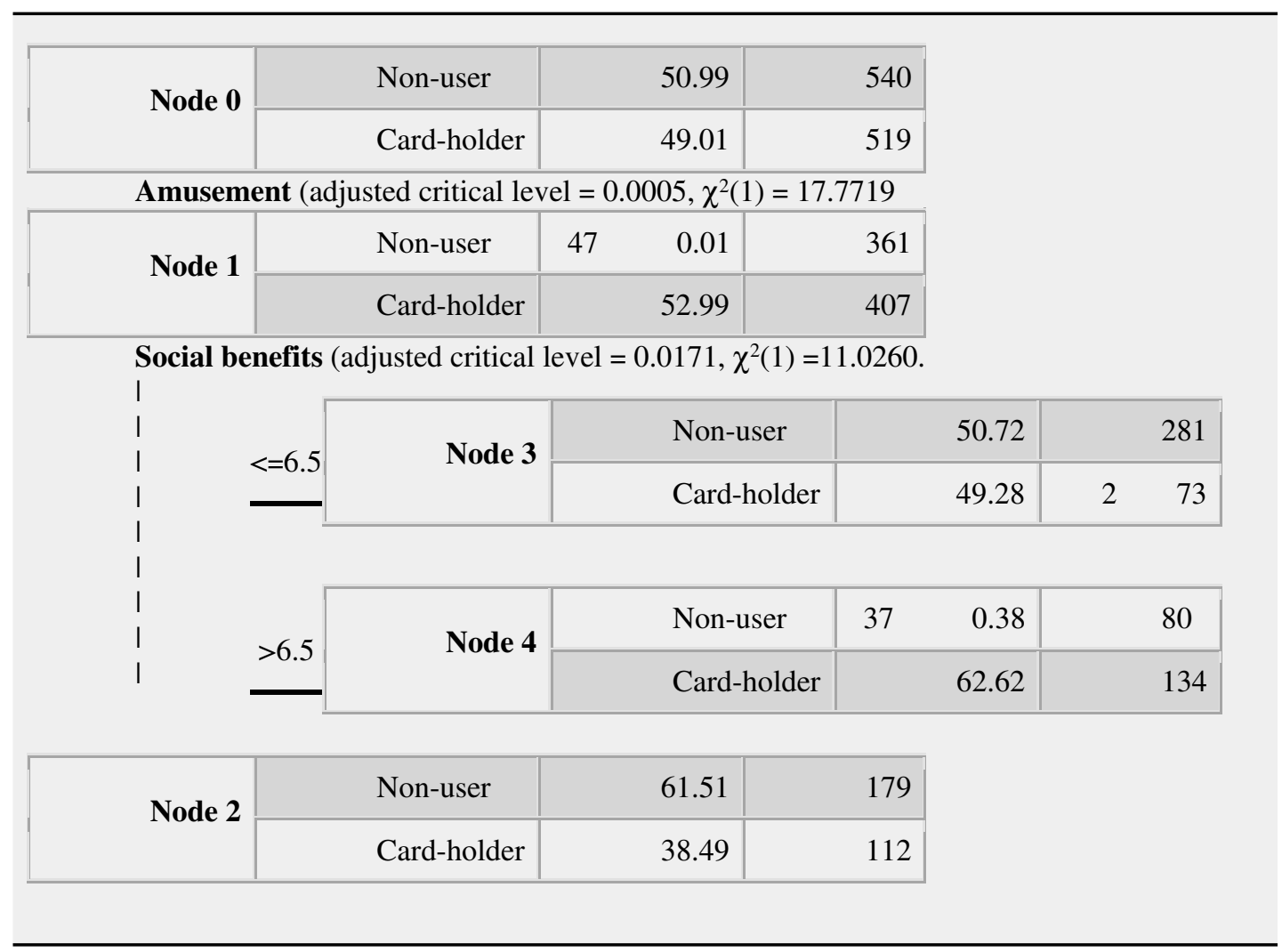


There are significant differences in the evaluation of the rewards between cardholders and non-users. This leads us to conclude that not offering certain prizes in the catalogs may condition people's nonparticipation.

The management of multisponsor loyalty programmes can be made more dynamic by adjusting the offer of rewards to users' requirements. The viability of offering novel or minority managed prizes such as solidarity, ecology, or services is revealed.

If the promoting programme company's goal is to capture new card-holders, their managers should consider the incorporation or reinforcement of other kinds of rewards: in this case, amusement intangibles prizes.

If the goal is to consolidate the current card-holders, the current offer of prizes could be maintained, incorporating novel rewards such as social benefits.

We consider the following limitation of the work: the available descriptive information about the typology of prizes used by multisponsor programmes, and their volume of exchange does not allow us to establish statistically representative conclusions about matching the prizes to the participants' interest. This would allow us to determine the potential of incorporating novel rewards into the current structures of the programmes in a segmented fashion. The evaluation of the prizes may vary as a function of the diverse sociodemographic profiles. In future developments of the investigation, it would be appropriate to establish the eventual relations between profiles and prizes. These relations would allow the differentiated management of the heterogeneity of consumers as a function of the different programme incentives.

\section{References and Notes}

1 Sharp, B. and Sharp, A. (1997) 'Loyalty programmes and their impact on repeat purchase loyalty patterns', International Journal of Research in Marketing, Vol. 14, pp. 73-86.

2 Bolton, R., Kannan, P. and Ramlett, D. (2000) 'Implications of loyalty programme membership and service experiences for customer retention and value', Journal of the Academy of Marketing Science, Vol. 28, No. 1, pp. 95-108.

3 Benavent, C. and Crie, D. (1998) 'Mesurer l'efficacité des cartes de fidélité', Décisions Marketing, Vol. 15(January-April), pp. 10-20.

4 Meyer-Waarden, L. (2002) 'Les Sources D'efficacité des Programmes de Fidélisation. Une Étude Empirique sur la Base d'un Panel Single Source', These de Doctorat, Université de Pau et des Pays de l'Adour-IAE, Académie de Bordeaux.

5 Leenheer, J., Bijmolt, T., Heerde, H. and Smidts, A. (2002) 'Do loyalty programmes enhance behavioural loyalty', Discussion Paper No. 65, Tilburg University, Center for Economic Research.

6 Cortinas, M., Elorz, M. and Mugica, J. M. (2005) 'Loyalty cards: Are retailers ignoring non-card-holder behaviour', European Retail Digest - Issue, Vol. 45(Spring), pp. 18-20.

7 Reinares, P. and Reinares, E. (2005) 'Empirical assessment of the benefits obtained in a loyalty programme applied to retailing', CD Proceedings of the International Retailing Conference, Academy of Marketing Science, Reims, France.

8 Ziliani, C. and Bellini, S. (2004) 'From loyalty cards to micro-marketing strategies: Where is Europe's retail industry heading', Journal of Targeting, Vol. 12, No. 3, pp. 281.

9 Meyer-Waarden, L. and Benavent, C. (2003) 'Les cartes de fidélité comme outils de segmentation et de ciblage. Le cas dúne enseigne de distribution', Decisions Marketing, Vol. 32(October-December), pp. 19-30.

10 O’brian, L. and Jones, C. (1995) 'Do rewards really create loyalty', Harvard Business Review, Vol. 73 (May-June), pp. 75-82.

11 Byrom, J. (2001) 'The role of loyalty card data within local marketing initiatives', International Journal of Retail \& Distribution Management, Vol. 29, No. 6/7, pp. 333-342.

12 Hart, S., Smith, A., Sparks, L. and Tzokas, N. (1999) 'Are loyalty card schemes a manifestation of relationship marketing', Journal of Marketing Management, Vol. 15, pp. 541-562.

13 Dowling, G. R. and Uncles, M. (1997) 'Do customer loyalty programmes really work', Sloan Management Review, Vol. 38, No. 4, pp. 71-82.

14 Roehm, M. L., Bolman Pullins, E. and Roehm Jr, H. A. (2002) 'Designing loyalty-building programmes for packaged goods brands', Journal of Marketing Research, Vol. 39, pp. 202-213.

15 Mimouni, A. and Volle, P. (2003) 'Bénéfices perçus de la fidélisation et qualité relationnelle: Une application exploratoire au secteur du transport aérien', Working Paper No. 313, Centre de Recherche, DMSP.

16 Yi, Y. and Jeon, H. (2003) 'Effects of loyalty programmes on value perception, programme loyalty, and brand loyalty', Journal of the Academy of Marketing Science, Vol. 31, No. 3, pp. 229-240.

17 Kivetz, R. and Simonson, I. (2002) 'Earning the right to indulge: Effort as a determinant of customer 
preferences toward frequency programme rewards', Journal of Marketing Research, Vol. 39, pp. 155-170.

18 Neslin, S. A. (2002) 'Sales Promotion, Relevant Knowledge Series', Marketing Science Institute, Cambridge, MA, pp. 67.

19 Shi, M. (2005) 'Managing consumer switching costs through loyalty incentives', Progress Report, Rotman School of Management, University of Toronto, Canada.

20 Hartmann, W. and Viard, B. (2005) 'Quantity-based price discrimination using frequency reward programmes', Summer Institute in Competitive Strategy, Conference presentation, University of California, Berkeley.

21 Reinares, P. (2006) 'Loyalty programme rewards as a key element of their management and positioning', Proceedings EMAC 2006, pp. 1-8.

22 Meyer-Waarden, L. and Benavent, C. (2006) 'La Théorie de la Motivation Extrinsèque et Intrinsèque Appliquée a la Problématique des Gratifications de Programmes de Fidelization', Proceedings AMF French Marketing Academy, Nantes, pp. 1-44.

23 Dreze, X. and Nunes, J. (2004) 'Using combinedcurrency prices to lower consumers perceived cost', Journal of Marketing Research, Vol. XLI(February), pp. 59-72.

24 Wansink, B. (2003) 'Developing a cost-effective brand loyalty programme', Journal of Advertising Research, Vol. 43, No. 3, pp. 301-309.

25 Wansink, B. and Seed, S. (2001) 'Making brand loyalty programmes succeed', Journal of Brand Management, Vol. 8, No. 2, pp. 211-222.

26 Sorman, D. (1998) 'The illusion of delayed incentives: Evaluating future effort-money transactions', Journal of Marketing Research, Vol. 35, No. 4, pp. 427-438.

27 Keh, H. T. and Lee, I. H. (2006) 'Do reward programmes build loyalty for services? The moderating effect of satisfaction on type and timing of rewards', Journal of Retailing, Vol. 82, No. 2, pp. $127-136$.

28 Wood, A. (2005) 'Loyalty - What can it really tell you', Database Marketing \& Customer Strategy Management, Vol. 13, No. 1, pp. 55-63.
29 Rosenbaum, M., Ostrom, A. and Kuntze, R. (2005) 'Loyalty programmes and a sense of community', The Journal of Services Marketing, Vol. 19, No. 4, pp. 222-233.

30 Hallberg, G. (2004) 'Is your loyalty programme really building loyalty? Why increasing emotional attachment, not just repeat buying, is key to maximizing success', Journal of Targeting, Measurement and Analysis for Marketing, Vol. 12, No. 3, pp. 231.

31 Wulf, K., Odekerken, G., Canniere, M. and Oppen, C. (2003) 'What drives consumer participation to loyalty programmes? A conjoint analytical approach', Journal of Relationship Marketing, Vol. 2, No. 1/2, pp. 69-83.

32 In contrast to other works, the evaluation of these 13 rewards is totally independent of the relative effort to obtain them. Far from being a limitation (interest in the reward is conditioned by the effort to obtain it), this is one of the goals of the work: in multisponsor programmes, there is no direct relation among the act of buying and a specific company and the reward obtained.

33 Galguera, L., Luna, D. and Méndez, M. P. (2006) 'Predictive segmentation in action. Using CHAID to segment loyalty card holders', International Journal of Market Research, Vol. 48, No. 4, pp. 459-479.

34 At first, we considered it more appropriate to carry out a principal components analysis to reduce the high number of initial variables, and later use the factor scores in discriminant analysis. This proposal, however, was rejected because of the low correlation among the independent variables, opting instead for multiple discriminant analysis.

35 Wedel, M. and Kamakura, W. A. (1999) 'Market segmentation: conceptual and methodological foundations', International Series Quantitative Marketing, part 2, Kluwer Academic Publishers, The Netherlands.

36 Magidson, J. (1994) 'The CHAID approach to segmentation modelling: Chi-squared automatic interaction detection', in: Bagozzi, R.P. (ed.) 'Advanced Methods of Marketing Research', Blackwell: Cambridge, pp. 118-159. 